\title{
EL TURISMO: \\ Doncella del Imperialismo
}

\author{
Geoffrey SKOLL \\ Buffalo State College (EEUU) \\ skollgr@buffalostate.edu
}

\section{TOURISM: Maiden of Imperialism}

Lo que podemos comprender del turismo, observándolo, estudiándolo, o practicándolo sugiere que antes que nada hablamos de una "actividad", de una práctica social que alude a "un otro escondido". De la misma forma que cantamos, o andamos en bicicleta, el turismo ha sido mistificado por el aura del dinero y los negocios. Por ese motivo, comprendemos que el turismo obedece exclusivamente a un "viaje rentado". Para sortear este obstáculo conceptual, es necesario traer a colación que entonces una cosa es el turismo (tourism), y otra es el "descubrimiento" (touring). Por desgracia, la literatura especializada en turismo ha prestado una atención desmedida sobre el turismo como forma comercial, y se ha olvidado de la segunda conceptualización.

Precisamente, el "descubrimiento" (Touring) ha estado presente a lo largo de los siglos en varias culturas y civilizaciones perdidas. Alejandro Magno viajaba para conquistar grandes territorios de la misma forma que los anglosajones antiguos se lanzaban a la conquista de lo desconocido como manera genuina de generar respeto y prestigio en sus respectivas comunidades (Korstanje, 2012). Empero es importante no dejar de lado que el turismo comercial, por el contrario, ha sido un resultado directo de la maduración capitalista y el triunfo inevitable de la burguesía europea en el siglo XIX. Hasta el punto de poder solidificar una pujante industria de millones de dólares, el arquetipo del usufructo financiero sobre el turismo nos remonta a Thomas Cook quien organizó los primeros viajes rentados en la Europa industrial.

No obstante, una mirada sociológica sugiere que el turismo permite ampliar los canales de circulación de bienes y la comoditización de los servicios. La sociedad capitalista encuentra en la comoditización su propia razón de ser. Una gran cantidad de commodities entran en juego en el sistema turístico. Por ejemplo, el automóvil reúne toda una serie de mercaderías, tecnologías para ser ofrecidas en forma abstracta, en un sólo producto. Si la industria 
automovilística vende autos, el turismo hace lo mismo con los servicios, forjando experiencias particularmente efímeras. En el año 1967, Guy Debord había previsto que el mundo del espectáculo iba a mezclarse, fusionarse y hacerse uno con la realidad social:

"The spectacle corresponds to the historical moment at which the commodity completes its colonization of social life [...] commodities are now all that there is to see; the world we see is the world of the commodity" (Debord 1967: 2942).

El sentido filosófico del todo que es nada más ni nada menos que la sociedad, sería colonizado por una forma estética de consumo masivo. No solo que nada escapa a los commodities, sino que el mundo mismo sería controlado por una "comoditización" realista. En este sentido las sospechas de Debord no eran muy diferentes a las de Georg Lukacs,

"the commodity can only be understood in its undistorted essence when it becomes the universal category of society as a whole. Only in this context does the reification produced by commodity relations assume a decisive importance both for the objective evolution of society and for the stance adopted by men towards it. Only then does the commodity become crucial for the subjugation of men's consciousness" (Lukacs 1923: 86).

El capitalismo cuadra los procesos de producción bajo el ala del dinero, pero éste no tiene validez sin el signo que le precede. Cuando la acumulación capitalista alcanza los puntos máximos de saturación, emerge el espectáculo como forma de relación global entre los integrantes del sistema. En palabras del mismo Debord, "the spectacle is capital accumulated to the point where it becomes image" (Debord 1967: 24 - 34). Lo cierto parece ser, que ambos Debord y Lukacs, enfatizan en la extraña dialéctica por medio de la cual el turista consume el mundo que él mismo fabrica. La complejidad de este proceso queda determinada por una producción que se consume así misma. Todo turista produce y consume el mismo espectáculo hasta el punto de hacer de la atracción una forma ideológica de expropiación. Como bien advertían Horkheimer y Adorno (1947), los atractivos turísticos funcionan como piezas ideológicas que legitiman la lealtad de la ciudadanía frente a sus formas de producción. Louis Althusser (1970: 43) reporta considera que el "espectáculo", y dentro de éste el turismo, forma parte de los "dispositivos ideológicos del estado". En perspectiva, el estado puede controlar nuestra consciencia como agentes de consumo, gracias al uso sistemático de la ideología, entendida esta última como un "sistema de creencias" orientadas a la propia legitimación sensible del mundo externo. El sentido impuesto de la realidad se encuentra condicionado por la validación de las propias ideas producidas por la ideología (Gouldner, 1976, 33).

En el fondo, la separación del estado respecto al mercado es una mera utopia. A través de la ideología, el estado y la mano invisible del mercado se funden en un mismo ethos, y se organizan de tal forma que se legitiman mutuamente. Un claro ejemplo de lo expuesto, es la relación camuflada entre las declaraciones de guerra en Oriente Medio, y el arribo de corporaciones financieras que hacen sus negocios luego de la retirada de las tropas. En este contexto, el turismo como forma global de comercio establece formas de complicidad conjunta entre el mundo de los negocios y el diseño de las noticias en el mundo informativo. Las formas ideológicas fabrican sentido en el espacio cultural y en ese proceso práctica y sentido se desdibujan. El turismo puede, entonces, comprenderse como un mecanismo ideológico por medio del cual, el viajero expande su universo material a otros espacios, también diseñados para darles recepción. Los parámetros discursivos de atracción como así las formas estereotipadas de consumo nada tienen que ver con la cultura receptora en muchos de los casos 
documentados por la investigación sociológica. El turismo que busca en el consumo de templos o ruinas de civilizaciones perdidas sirve de ejemplo para explicar la morfología del mundo del commodity. Las construcciones humanas fueron parte ideológica de una cultura que ya no existe. Sin embargo, el turismo introduce no solo una nueva interpretación sino que impone un sentido siempre presente del pasado. Estos espacios de consumo condensan tres elementos vitales, la materialidad que representan las ruinas, el turista que se vincula a la experiencia subjetiva y la cultura de la población receptiva. Althusser admitira que:

"[This] is what happens to the 'individuals' who live in ideology, i.e. in a determinate (religious, ethical, etc.) representation of the world whose imaginary distortion depends on their imaginary relation to the conditions of existence, in other words, in the last instance, to the relations of production and to class relations $[\ldots]$ I shall say that this imaginary relation is itself endowed with a material existence" (Althusser 1970: 166-7).

Partiendo del supuesto que las ideologías construyen subjetividad y personas, no menos cierto es que esa subjetividad encuentra sustento simbólico en el hecho de que el sujeto entiende al mundo bajo el prisma ideológico. Este proceso siempre es de interpelación. $\mathrm{Cu}$ ando un viajero se traslada a otra cultura, éste está interpelando al otro en forma inquisitiva. Las diferencias culturales pueden ser amplias o no, el problema subyace en que el turismo "vende culturas", usufructuando al shock como forma de intercambio. La tesis central de este trabajo es que a la vez que el turista interpela a la sociedad receptora con su mirada, su misma subjetividad queda atada a la necesidad de espectáculo que éste mismo consume "siendo turista". Los viajeros pasan, de esta forma, de ser meros consumidores a objetos consumibles.

Siguiendo este argumento, Jean Paul Sartre pone un ejemplo para entender mejor lo expuesto anteponiendo la "metáfora" del round de boxeo. En forma general, entendemos que el boxeo es un deporte que pone a dos oponentes en un ring, ambos quedan subordinados al grado de violencia que pueden inflingirse. Cada uno, como los actores de la sociedad misma, queda sujeto a la forma de exteriorizar esa violencia en el otro (Sartre 1985: 25). En ese diálogo, se da lo que el filósofo llama "violencia fundamental", la cual representa la violencia solapada en todas las relaciones sociales. Cualquier round de boxeo, agrega Sartre no se trata de dos oponentes pegándose, sino de toda una infraestructura puesta al servicio de un espectáculo. El sentido conferido al ser boxeador que el público puede disfrutar si paga su entrada, es a lo que Sartre denomina "violencia fundamental". En parte, los boxeadores son commodities y ocupan ese rol porque su labor va más allá de sus posibilidades de adquirir beneficios por su trabajo. El acto violento deja de ser real, a no ser por la necesidad de usufructuarlo para adquirir dinero. Los boxeadores no se pelean porque se odien, sino porque perciben un dinero a cambio.

Empero ello sugiere una pregunta por demás interesante, ¿cuál es la función de la ideología?. En las sociedades capitalistas, la ideología no solo funciona como mecanismo reproductor de las relaciones de clase, sino que ordena a las personas dentro de esas diferentes clases para poder garantizar la circulación de los bienes producidos. El turista es antes que nada, un trabajador, pero el "trabajador del turismo" toma un rol excepcional. Adquieren un rol principal como trabajadores poniendo su labor en post del funcionamiento de la industria, a diferencia de los turistas quienes parecen ser una "fuerza colectiva" desprovisto de cualquier afiliación o conciencia de clase (Jameson, 2011). Como miembro del sistema burgués, y a diferencia de la fuerza laboral, el turista queda imposibilitado de poder tener una conciencia de clase, debido a que él mismo es producto del mercado globalizado. Cuando la persona se asume en el rol de turista, ésta abandona su individualidad para abrazar construc- 
ciones colectivas fabricadas por el capitalismo. Frederic Jameson, se refiere al capítulo 13 del Capital Vol I, de la siguiente forma:

"Moreover, the co-operation of wage-labourers is entirely brought about by the capital that employs them. Their unification into one single productive body, and the establishment of a connection between their individual functions, lies outside their competence. These things are not their own act, but the act of the capital that brings them together and maintains them in that situation. Hence the interconnection between their various labours confronts them, in the realm of ideas [emphasis added], as a plan drawn up by the capitalist, and, in practice, as his authority, as the powerful will of a being outside them, who subjects their activity to his purpose" (Marx 1867: 449-450).

Lo que el Marx de Jameson dice, es que "los efectos colosales" de la cooperación por medio de los cuales se pueden construir las grandes civilizaciones han sido alteradas bajo el monopolio del signo. Tales efectos colosales han dado forma a nuevas expresiones que desembocan en las atracciones turísticas. El sentido imperial de ostentación y la función que esa construcción ha tenido en el pasado, queda supeditado a una nueva lógica de producción política e ideológica, la cual se encuentra enraizada en el capitalismo.

Por ese motivo, Marx y Engels en el Manifiesto exhiben sus respectivas preocupaciones por la expansión misma del capital. De alguna u otra manera, el capital parece condenado no solo a replicarse, sino a globalizarse. Siguiendo a Debord, en nuestro "mundo del espectáculo", el turismo es tanto un negocio productor de divisas, como un instrumento para controlar las voluntades humanas. Desde la perspectiva de los negocios, el turismo permite que se aceleren los medios productivos y la circulación de bienes, empero desde una postura política, el turismo genera códigos específicos de adoctrinamiento los cuales no solo son aprovechados por los mercados, sino por el mismo estado nacional. Porque el capital se ha expandido hacia los confines del mundo, desdibujando todas las fronteras pre-existentes, resulta la tesis que alienados en nuestra propia existencia, todos somos turistas de nuestras propias vidas.

\section{Bibliografía}

\section{ALTHUSSER, L.}

1971 Ideology and Ideological State Apparatuses. In Lenin and Philosophy and Other Essays. Translated by Ben Brewster. New York: Monthly Review Press.

DEBORD, G.

1994 The Society of the Spectacle. Translated by Donald Nicholson-Smith. New York, Zone Books.

GOULDNER, Alvin W.

1976 The Dialectic of Ideology and Technology: The Origins, Grammar, and Future of Ideology. New York: Seabury Press.

HORKHEIMER, $M$ \& ADORNO, T

2002 Dialectic of Enlightenment: Philosophical Fragments. Edited by Gunzelin Schmid Noerr; translated by Edmund Jephcott. Stanford, CA: Stanford University Press.

JAMESON, F.

2011 Representing Capital: A Commentary on Volume One. New York: Verso.

KORSTANJE, M E.

2012 Examining the Norse Mythology and the Archetype of Odin: The Inception of Grand Tour.

LUKACS, G Turizam: An International Interdisciplinary Journal 60(4): 369-384.

1971 History and Class Consciousness. Translated by Rodney Livingstone. Cambridge, MA: MIT Press. 
MARX, K

1976 Capital Volume I: A Critique of Political Economy. Translated by Ben Fowkes. New York: New Left review and Penguin Books.

MARX, $\mathrm{K}$ and ENGELS F.

1848 Manifesto of the Communist Party. http://www.marxists.org/archive/marx/works/1848/ communist-manifesto/ch01.htm

SARTRE, J-P

2006 Critique of Dialectical Reason II. Translated by Quentin Hoare; edited by Arlette Elkaim-Sartre. New York, NY: Verso. World Tourism Organization. 2013. China - the New Number One Source Market in the World. Press release April 4. http://media.unwto.org/en/press-release/2013-04-04/chinanew-number-one-tourism-source-market-world.

\section{$\cos$}

